Reprod. Nutr. Dévelop., 1988, 28 (1), 97-98.

\title{
L'utilisation des glucides pariétaux du foin, du son et de la pulpe de betterave chez le poney alimenté à l'entretien ou ad libitum
}

Carole DROGOUL, F. FAURIE, J. L. TISSERAND

Laboratoire de Recherches de la Chaire de Zootechnie E.N.S.S.A.A., I.N.R.A., 26, bd Docteur Petitjean, 21000 Dijon, France.

Summary. The estimation of total digestibility of 3 feeds (hay, dried sugar beet pulp and wheat bran) in ponies showed that the cell-wall constituents (carbohydrates) of the pulps were digested quite well but those of the bran unsatisfactorily. The level of feed intake modified the digestibility of cell wall constituents.

Introduction. Le son de blé et la pulpe de betterave sont couramment utilisés comme matière première pour les aliments composés des chevaux. Or, peu d'études (Wolter et al., 1979) ont été réalisées pour connaître la valeur de ces aliments. C'est pourquoi, nous avons mesuré l'utilisation digestive du foin de luzernedactyle, de la pulpe de betterave déshydratée et du son de blé chez le poney adulte alimenté au niveau de l'entretien ou à volonté.

Matériel et méthodes. La digestibilité est mesurée in vivo sur 6 poneys adultes mâles entiers de race Shetland pesant entre 180 et $200 \mathrm{~kg}, 3$ d'entre eux étant munis d'une canule permanente du caecum. Ils reçoivent, au cours de trois périodes successives ( 21 jours d'accoutumance +10 jours de mesures), les régimes suivants : $1^{\circ}$ Foin de luzerne-dactyle seul, $2^{\circ}$ Foin $(40 \%)+$ pulpe de betterave déshydratée $(60 \%), 3^{\circ}$ Foin $(40 \%)+$ son de blé $(60 \%)$; l'eau et les minéraux (pierre à lécher) sont laissés à volonté.

Deux séries de mesures sont effectuées : une au niveau de l'entretien selon les recommandations de I'I.N.R.A. (1984) et ad libitum (10\% refus). Deux repas sont distribués par jour en mettant en même temps foin et concentré à la disposition des animaux. Les essais sont conduits selon un dispositif en carré latin. Lors de la distribution à volonté le rapport fourrage : concentré est respecté par ajustement quotidien des quantités d'aliments distribuées.

Les aliments, les refus et les fèces individuels sont échantillonnés quotidiennent pour doser la teneur en matière sèche. Les échantillons secs sont cumulés pour analyser leur fraction pariétale par la méthode de Weende et par la méthode de Van Soest (Van Soest et Wine, 1967) adaptée à un appareil de dosage automatique Fibertec, cela pour chaque période et par animal. 
Résultats et discussion. Au niveau de l'entretien, par rapport au régime foin, l'addition de pulpes de betterave augmente de façon similaire les digestibilités de la matière organique (MO) et des parois (NDF) alors qu'avec le son, la digestibilité de la MO est légèrement augmentée et celle des parois diminue faiblement. Après déduction des valeurs obtenues avec le régime foin, les digestibilités calculées pour la pulpe de betterave et le son de blé (tabl. 1) sont très voisines de celles publiées par Wolter et al. (1979). II ne semble pas qu'il y ait, dans ce cas, de digestibilité associative.

TABL. 1. - Composition, ingestion et digestibilité des rations et des aliments.

\begin{tabular}{|c|c|c|c|c|c|c|}
\hline & Entretien & Ad libitum & Entretien & Ad libitum & Entretien & Ad libitum \\
\hline Rations & \multicolumn{2}{|c|}{ Foin } & \multicolumn{2}{|c|}{$\begin{array}{l}\text { Foin }+ \text { pulpes } \\
\text { de betterave }\end{array}$} & \multicolumn{2}{|c|}{ Foin + son de blé } \\
\hline $\begin{array}{l}\text { Matière sèche ingérée : } \\
\mathrm{g} / \mathrm{j} \\
\mathrm{g} / \mathrm{kg} \mathrm{P} 0,75 \\
\text { Digestibilité : } \\
\text { Matière organique } \\
\text { Cellulose brute } \\
\text { Parois (NDF) }\end{array}$ & $\begin{array}{l}3116 \\
62 \\
\\
0,56 \\
0,44 \\
0,48\end{array}$ & $\begin{array}{l}5913 \\
111 \\
\\
0,53 \\
0,36 \\
0,41\end{array}$ & $\begin{array}{l}2482 \\
43 \\
\\
0,71 \\
0,58 \\
0,67\end{array}$ & $\begin{array}{l}4794 \\
92 \\
\\
0,61 \\
0,42 \\
0,49\end{array}$ & $\begin{array}{c}2501 \\
51 \\
\\
0,60 \\
0,38 \\
0,46\end{array}$ & $\begin{array}{l}5595 \\
105 \\
\\
0,59 \\
0,32 \\
0,42\end{array}$ \\
\hline Aliments & \multicolumn{2}{|c|}{ Foin } & \multicolumn{2}{|c|}{ Pulpes de betterave } & \multicolumn{2}{|c|}{ Son de blé } \\
\hline $\begin{array}{l}\text { Composition : } \\
\text { Cellulose brute } \\
\text { Parois (NDF) }\end{array}$ & 39,6 & 37,3 & 20,8 & 21,1 & 13,3 & 13,7 \\
\hline Lignocellulose (ADF) & 44,6 & 40,3 & 23,3 & 23,2 & 16,3 & 16,0 \\
\hline $\begin{array}{c}\text { Lignine (ADL) } \\
\text { Digestibilité : (1) }\end{array}$ & 9,6 & 8,7 & 2,9 & 4,4 & 4,4 & 4,9 \\
\hline $\begin{array}{l}\text { Matière organique } \\
\text { Cellulose brute } \\
\text { Parois (NDF) }\end{array}$ & $\begin{array}{l}0,55 \\
0,44 \\
0,48\end{array}$ & $\begin{array}{l}0,53 \\
0,36 \\
0,41\end{array}$ & $\begin{array}{l}0,82 \\
0,80 \\
0,83\end{array}$ & $\begin{array}{l}0,74(2) \\
0,68(2) \\
0,67(2)\end{array}$ & $\begin{array}{l}0,63 \\
0,26 \\
0,45\end{array}$ & $\begin{array}{l}0,63 \\
0,17 \\
0,42\end{array}$ \\
\hline
\end{tabular}

(1) Digestibilité calculée par différence. (2) Valeurs calculées sur 5 poneys, les résultats de l'un des sujets s'avèrent aberrants.

L'alimentation à volonté entraîne une très forte augmentation de l'ingestion avec une très grande variabilité entre individus. Elle provoque, par rapport à l'entretien, une diminution de la digestibilité de la matière organique et des parois qui est surtout importante dans le cas du régime foin + pulpes. Par contre, avec le régime foin + son de blé, malgré une très forte augmentation de la quantité de matière sèche ingérée ad libitum $(220 \%)$, il n'y a pas de modifications de la digestibilité de la matière organique et la diminution de la digestibilité des parois reste limitée. Incidemment cette étude, portant il est vrai sur un petit nombre de résultats, ne fait apparaître aucune différence entre sujets fistulés ou non.

En conclusion, le cheval semble bien utiliser les glucides pariétaux de la pulpe de betterave mais beaucoup moins ceux du son de blé. Les équidés semblent donc digérer la pulpe comme les ruminants mais un peu moins bien le son de blé.

I.N.R.A., 1984, In Le Cheval, Jarrige R., Martin-Rosset W., 689 p.

Van Soest P. J., Wine R. H., 1967. J. Assoc. offic. anal, Chem., 50, 50-55.

Wolter R., Durix A., Letourneau T. L., Carcelem H., 1979. Ann. Zootech., 28, 93-100. 